\title{
Outcomes of axillary artery side graft cannulation for extracorporeal membrane oxygenation
}

\author{
Themistokles Chamogeorgakis, MD, ${ }^{\text {a,b,c }}$ Brian Lima, MD, ${ }^{\mathrm{a}}$ Alexis E. Shafii, MD,,${ }^{\mathrm{a}, \mathrm{c}}$ \\ Dave Nagpal, MD, ${ }^{\mathrm{a}}$ Julie A. Pokersnik, CCP, ${ }^{\mathrm{a}}$ Jose L. Navia, MD, ${ }^{\mathrm{a}}$ David Mason, MD, ${ }^{\mathrm{a}}$ and \\ Gonzalo V. Gonzalez-Stawinski, MD ${ }^{\mathrm{a}, \mathrm{c}}$
}

Objective: To determine the safety, efficacy, and frequency of side graft axillary artery cannulation for extracorporeal membrane oxygenation support and compare it with other cannulation techniques.

\begin{abstract}
Methods: From January 2001 to October 2011, 308 adult patients were supported with extracorporeal membrane oxygenation at a single center. In 81 patients (26.3\%), the extracorporeal membrane oxygenation circuit was composed of an arterial inflow by a side graft sewn to the axillary artery. Of the 308 patients, 166 (53.9\%) underwent femoral arterial cannulation and $61(19.8 \%)$ underwent ascending aortic cannulation The pertinent variables and postprocedural events were retrospectively analyzed in this cohort of patients.
\end{abstract}

\begin{abstract}
Results: The most common complication in the axillary artery group was hyperperfusion syndrome of the ipsilateral upper extremity $(n=20,24.7 \%)$, followed by bleeding from the arterial outflow graft $(n=14,17.3 \%)$. Lower extremity ischemia and fasciotomy were more frequent after femoral arterial cannulation $(\mathrm{n}=27,16 \%$, and $\mathrm{n}=18,10.8 \%$, respectively). The predictors for a poor in-hospital outcome for the entire group of patients were age and postoperative cerebral vascular accident. The cannulation method was not a predictor of in-hospital outcomes.
\end{abstract}

Conclusions: Extracorporeal membrane oxygenation support with side graft axillary artery technique was more frequently associated with hyperperfusion syndrome than other cannulation sites. Lower extremity ischemia and compartment syndrome was more common after femoral arterial cannulation. (J Thorac Cardiovasc Surg 2013;145:1088-92)

The indications for extracorporeal membrane oxygenation (ECMO) have been well established. ${ }^{1-3}$ Access for the initiation of ECMO can be challenging, and a number of approaches have been reported. For patients with postcardiotomy shock, central cannulation is typically used, because it is easy to switch the cardiopulmonary bypass circuit to ECMO with the existing cannulas. Alternatively, in cases in which immediate support is necessary, such as acute cardiogenic shock after myocardial infarction, percutaneous access can be achieved by way of a peripheral vessel using the Seldinger technique or open arteriotomy.

The disadvantages of the latter approaches lie in the interference of distal flow to the cannulated limb, resulting in ischemia. This has previously been reported as a common complication of direct cannula placement with ECMO. In

From the Department of Thoracic and Cardiovascular Surgery, ${ }^{\mathrm{a}}$ Cleveland Clinic, Cleveland, Ohio; National and Kapodistrian, ${ }^{\mathrm{b}}$ University of Athens, Athens, Greece; and Department of Thoracic and Cardiovascular Surgery, ${ }^{\mathrm{c}}$ Baylor University Medical Center, Dallas, Tex.

Disclosures: Authors have nothing to disclose with regard to commercial support. Received for publication May 7, 2012; revisions received Aug 17, 2012; accepted for publication Aug 24, 2012; available ahead of print Sept 24, 2012.

Address for reprints: Gonzalo V. Gonzalez-Stawinski, MD, Department of Thoracic and Cardiovascular Surgery, Baylor University Medical Center, 3900 Junius St, Suite 605, Dallas, TX 75246 (E-mail: Gonzo.Gonzalez@baylorhealth.edu).

$0022-5223 / \$ 36.00$

Copyright (c) 2013 by The American Association for Thoracic Surgery

http://dx.doi.org/10.1016/j.jtcvs.2012.08.070 an effort to minimize this, some have proposed using distal perfusion cannulas to guarantee limb perfusion or placing a side graft on the target artery. ${ }^{4}$

We have previously reported on the use of a side graft on the axillary artery as a choice for ECMO. ${ }^{5}$ The advantages to using this vessel include the lack of atherosclerosis, the guarantee of forward flow into the aorta, potentially minimizing atherosclerotic embolization, and the preferential delivery of oxygenated blood to the heart and brain. However, although our initial report focused on the feasibility of using this technique for ECMO, the outcomes associated with this cannulation strategy have never been studied. Therefore, the purpose of the present study was to analyze the outcomes associated with the use of a side graft on the axillary artery as a cannulation technique for venoarterial (VA) ECMO in a large patient cohort.

\section{MATERIALS AND METHODS}

A retrospective chart review was conducted of all patients who had received ECMO from January 2001 to October 2011 at Cleveland Clinic Foundation (Cleveland, Ohio). A review of patient charts provided demographics, the indication for VA ECMO support, duration of support, ECMO flow (documented at the first instance after ECMO initiation), partial oxygen arterial pressure measured within 4 hours after ECMO initiation, and short- and long-term outcomes, including limb complications related to arterial cannulation. The institutional review board provided written approval for the present study. 


\section{Abbreviations and Acronyms \\ $\mathrm{ECMO}=$ extracorporeal membrane oxygenation \\ $\mathrm{VA}=$ venoarterial}

\section{Cannulation Strategy and Technique}

The arterial cannulation strategy varied from case to case. For patients with ongoing chest compression, we used femoral arterial cannulation percutaneously placed for VA ECMO support. For postcardiotomy cases, we preferred central aortic cannulation as the first choice. However, if the axillary artery had been previously exposed before sternal entry in redo sternotomy cases or complex aortic arch reconstruction requiring deep hypothermia with antegrade cerebral perfusion was undertaken, we used the axillary artery.

The technique of side grafting the axillary artery for VA ECMO support has been previously described. ${ }^{6}$ In brief, the axillary artery was exposed below the clavicle, and, after administration of $5000 \mathrm{U}$ of heparin, an 8-mm hemashield graft was sewn in an end-to-side fashion. Venous drainage was achieved with either a long $20 \mathrm{~F}$ or $24 \mathrm{~F}$ cannula (Edward Lifesciences, Irvine, Calif) placed in the common femoral vein or right atrium when the chest was left open after median sternotomy.

\section{ECMO Management}

The intensive care unit protocol for VA ECMO patients in our institution has been previously reported. ${ }^{7}$ A heparin infusion was initiated at $400 \mathrm{U} / \mathrm{hr}$ once the chest was closed and all major bleeding had subsided, targeting a partial thromboplastin time of 55 to 65 seconds. If a patient could maintain appropriate hemodynamics and respiratory function with minimal inotropic support, the patient was considered for ECMO separation. Also, it was necessary to withdraw ECMO support if survival was unlikely.

\section{Definitions}

Hyperperfusion syndrome was defined as an ipsilateral, to the side of the arterial cannulation, edematous limb that was hyperemic and warm to touch. Compartment syndrome was defined as the more serious presentation of hyperperfusion syndrome in which the high compartment pressure causes secondary extremity ischemia. Arm ischemia was defined as a cold, pale, and/or mottled ipsilateral extremity due to decreased arterial blood flow. For the purposes of the present analysis, bleeding was considered present if exploration of the axillary artery cannulation site was necessary. Finally, stroke was defined as any central neurologic deficit diagnosed by clinical examination and/or radiologic imaging.

\section{Statistical Analysis}

Continuous variables are expressed as the mean values \pm standard deviation and were compared using the $t$ test. Categorical values are expressed as percentages and were compared using the $\chi^{2}$ test or Fisher's exact test, as appropriate. Multivariate regression analysis for in-hospital survival was undertaken for the entire group of patients receiving VA ECMO support. The variables of the entire group of patients were evaluated, first using univariate and then multivariate analysis. Model selection was done with a backward stepwise method, starting from all variables with a $P$ value $<.05$ on univariate analysis. The model was confirmed using forward selection.

\section{RESULTS}

\section{Indications for VA ECMO}

From January 2001 to October 2011, 429 patients underwent ECMO support for a variety of diagnoses at our institution. Of the 429 patients, 62 received venovenous ECMO for respiratory failure, and 26 received right ventricular support during left ventricular assist device placement for temporary right ventricular failure. Of the 341 patients receiving VA ECMO support, 33 did not have sufficient data for statistical analysis and were excluded from the present retrospective review.

Of the 308 patients who constituted the basis of our review, 81 underwent axillary cannulation (26.3\%), 166 $(53.9 \%)$ underwent femoral arterial cannulation, and 61 $(19.8 \%)$ underwent ascending aortic cannulation. The indications for ECMO support included postcardiotomy shock after major cardiac procedures $(\mathrm{n}=173,56.2 \%)$, postinfarction cardiogenic shock $(\mathrm{n}=55,17.9 \%)$, decompensated cardiomyopathy $(\mathrm{n}=44,14.3 \%)$, respiratory failure $(\mathrm{n}=21,6.8 \%)$, and various other reasons $(\mathrm{n}=15,4.9 \%$; Table 1$)$.

\section{Arterial Cannulation Complications}

Hyperperfusion syndrome was more common with the use of a side graft on the axillary artery $(n=20$, $24.7 \%$; Table 1). Of the 20 patients who developed hyperperfusion syndrome, 4 developed compartment syndrome of the limb. In 6 cases, the arterial outflow site had to be relocated ( 3 to the femoral artery, 2 to the aorta, and 1 to the contralateral axillary artery). These procedures were performed because compartment syndrome developed despite nonoperative management. Although 2 patients required upper extremity fasciotomy for compartment syndrome despite graft relocation, no additional action was taken for 2 other patients because of multisystem organ failure progression. Five patients with hyperperfusion of an upper extremity had arterial bleeding from the axillary side graft compromising the venous drainage. In 3 cases, arm swelling was effectively treated with wound exploration and hematoma evacuation. Another patient had proximal innominate artery stenosis that was missed preoperatively. Nine patients continued to have noncritical arm swelling that was effectively addressed with arm elevation. With additional analysis of the axillary artery patient group, we did not identify any variables that were specifically related to the hyperperfusion group. Furthermore, ECMO flow was not different between the hyperperfusion and the nonswollen arm group $(3.6 \pm 0.67$ vs $3.5 \pm 0.93 \mathrm{~L} / \mathrm{min}$, respectively; $P=.681)$.

Bleeding from the cannulation site was more common after axillary artery cannulation $(\mathrm{n}=14,17.3 \%)$; it typically occurred within 24 hours after VA ECMO initiation. This complication was treated with surgical exploration, hematoma evacuation, and control of bleeding by suturing anastomotic bleeding points. In cases of generalized coagulopathy, blood product transfusion was necessary, along with application of topical hemostatic agents and drain placement in the surgical wound. 
TABLE 1. Patient characteristics

\begin{tabular}{lcccc}
\hline \multicolumn{1}{c}{ Variable } & $\begin{array}{c}\text { Axillary } \\
(\mathbf{n}=\mathbf{8 1})\end{array}$ & $\begin{array}{c}\text { Femoral } \\
(\mathbf{n}=\mathbf{1 6 6})\end{array}$ & $\begin{array}{c}\text { Central } \\
(\mathbf{n = 6 1 )}\end{array}$ & $\begin{array}{c}\boldsymbol{P} \\
\text { value }\end{array}$ \\
\hline Demographics & & & & \\
Men & $47(58)$ & $119(71.7)$ & $31(50.8)$ & .006 \\
Age (y) & $60.3 \pm 15.6$ & $56.4 \pm 14.7$ & $62.1 \pm 13.6$ & .018 \\
HTN & $48(59.3)$ & $63(38)$ & $37(60.7)$ & .001 \\
PVD & $10(12.3)$ & $14(8.4)$ & $8(13.1)$ & NS \\
CVA & $5(6.2)$ & $9(5.4)$ & $2(3.3)$ & NS \\
Renal failure & $5(6.2)$ & $35(20.9)$ & $11(18)$ & .011 \\
Indication & & & & \\
After cardiotomy & $50(61.7)$ & $66(39.8)$ & $57(93.4)$ & $<.001$ \\
After infarction & $13(16)$ & $41(24.7)$ & $1(1.6)$ & $<.001$ \\
Cardiomyopathy & $4(4.9)$ & $39(23.5)$ & $1(1.6)$ & $<.001$ \\
Respiratory failure & $11(13.6)$ & $9(5.4)$ & $1(1.6)$ & .012 \\
Other & $3(3.7)$ & $11(6.6)$ & $1(1.6)$ & NS \\
Outcome & & & & \\
In-hospital mortality & $62(76.5)$ & $107(64.5)$ & $41(67.2)$ & NS \\
CVA (postoperative) & $5(6.2)$ & $32(19.3)$ & $13(21.3)$ & .016 \\
Limb complications & & & & \\
Hyperperfusion & $20(24.7)$ & $8(4.9)$ & $1(1.6)$ & $<.001$ \\
Ischemia & $1(1.2)$ & $27(16.3)$ & $3(4.9)$ & $<.001$ \\
Fasciotomy & $2(2.5)$ & $18(10.8)$ & $2(3.3)$ & .024 \\
Bleeding & $14(17.3)$ & $9(5.4)$ & $1(1.6)$ & .001 \\
\hline D & & &
\end{tabular}

Data presented as $\mathrm{n}(\%)$ or mean \pm standard deviation. $C V A$, Cerebral vascular accident; $H T N$, hypertension; $N S$, not significant; $P V D$, peripheral vascular disease.

Lower extremity ischemia was more common after femoral cannulation. Finally, the frequency of lower extremity fasciotomy for compartment syndrome was greater after femoral cannulation (Table 1).

\section{Weaning and Survival}

Of the 308 patients supported with VA ECMO, 98 $(31.8 \%)$ survived to hospital discharge. Univariate analysis identified age, hypertension, postoperative cerebral vascular accident, and cardiomyopathy as independent predictors for in-hospital outcome (Table 2). Age and postoperative cerebral vascular accident were independent predictors for a poor outcome on multivariate analysis (Table 3 ). The cannulation method was not an in-hospital outcome predictor.

For postinfarction and postcardiotomy cases, achieving adequate left ventricular decompression is very important

TABLE 2. Univariate analysis for in-hospital survival of patients supported with VA ECMO

\begin{tabular}{lccr}
\hline \multicolumn{1}{c}{ Variable } & OR & \multicolumn{1}{c}{$\mathbf{9 5 \%}$ CI } & P value \\
\hline Age & 1.036 & $1.019-1.054$ & $<.001$ \\
Hypertension & 2.146 & $1.019-1.054$ & .003 \\
PVD & 3.782 & $1.288-11.105$ & .016 \\
Cardiomyopathy & 0.503 & $0.263-0.964$ & .038 \\
Postoperative CVA & 2.399 & $1.116-5.160$ & .025 \\
\hline
\end{tabular}

$C I$, Confidence interval; $C V A$, cerebral vascular accident; $E C M O$, extracorporeal membrane oxygenation; $O R$, odds ratio; $P V D$, peripheral vascular disease; $V A$, venoarterial.
TABLE 3. Multivariate analysis for in-hospital survival of patients supported with VA ECMO

\begin{tabular}{lccr}
\hline \multicolumn{1}{c}{ Variable } & OR & $\mathbf{9 5} \%$ CI & $\boldsymbol{P}$ value \\
\hline Age & 1.036 & $1.018-1.054$ & $<.001$ \\
Postoperative CVA & 2.340 & $1.067-5.129$ & .034 \\
\hline
\end{tabular}

$C I$, Confidence interval; $C V A$, cerebral vascular accident; $E C M O$, extracorporeal membrane oxygenation; $V A$, venoarterial.

to increase the chance of successful weaning from ECMO. Adequate venous drainage with the largest possible venous cannula size prevents cardiac distention; however, this occurs in a large number of patients. In patients with severe pulmonary edema, left atrial or pulmonary artery decompression is an option. In our group, 4 patients $(1.3 \%)$ developed severe pulmonary edema from left ventricular distention. Pulmonary artery ( 2 cases) and left atrial decompression with a transeptal approach ( 2 cases) was performed with a percutaneously placed 20F cannula (Edward Lifesciences) from the common femoral or internal jugular vein.

Of the 81 patients with an axillary side graft, $25(30.9 \%)$ were successfully weaned from VA ECMO, and of those, 14 patients $(17.3 \%)$ survived to hospital discharge. Another 14 patients $(17.3 \%)$ were successfully bridged to a mechanical circulatory support device $(\mathrm{n}=8)$ or transplantation (lung in 4 , heart in 1, and heart and lung in 1). Of the patients who were bridged to a ventricular assist device or transplantation, $5(6.2 \%)$ survived to hospital discharge. The overall survival to discharge was $23.5 \%(n=19)$. The causes of inhospital death included multiorgan system failure in 57 $(70.4 \%)$ and stroke in $5(6.2 \%)$.

Of the 19 patients with an axillary artery side graft who survived, $2(2.5 \%)$ developed brachial plexopathy that improved with time. No cases of axillary graft stump infection or ipsilateral upper extremity ischemia had developed at the last follow-up examination (mean, 6.6 months).

\section{Adequacy of VA ECMO Support Provided by Axillary Cannulation}

The adequacy of support provided by the axillary artery was assessed according to the ECMO flow and partial oxygen arterial pressure within 4 hours after ECMO initiation. No ECMO flow difference $(3.53 \pm 0.86$ vs $3.73 \pm 0.86 \mathrm{~L} /$ min, respectively, $P=.117$ ) was seen between the axillary group and entire group supported using the 3 different arterial cannulation techniques. Similarly, no partial oxygen arterial pressure difference was found between the 2 groups $(309.89 \pm 85.19$ vs $326.89 \pm 102.78 \mathrm{~mm} \mathrm{Hg} ; P=.172)$.

\section{DISCUSSION}

The most significant finding associated with the present study was the previously unreported complication of hyperperfusion syndrome associated with using a side graft technique on the axillary artery as an outflow site for VA ECMO 
support. This event occurred in nearly $20 \%$ of the patients, with almost one half of those requiring some type of intervention to treat compartment syndrome. However, the incidence of extremity ischemia and compartment syndrome was greater with femoral cannulation.

The reasons for the development of hyperperfusion syndrome are multiple and can be broadly divided into 2 categories: (1) those causes resulting from arterial outflow obstruction; and (2) those associated with venous outflow obstruction. Among the arterial obstructive causes, the technical problems associated with construction of the anastomosis between the side graft and axillary artery is one issue. If, while creating the side graft to artery anastomosis, a problem occurs with the toe portion of this procedure, an axillary artery can be narrowed, causing a reduction in lumen size. This can result in preferential flow down the arm. A similar pattern can be expected with prolonged axillary graft use on the axillary artery in patients with atherosclerotic aortic arch disease and/or acute type A dissections in which the head vessels are involved. Venous obstructive causes can include bleeding into the surrounding space, causing a compressive hematoma, or if drainage to the arm is impeded by either a venous cannula or deep vein thrombus, or both.

How to respond to hyperperfusion syndrome is equally as important as diagnosing it because, as noted in our experience, a portion of these patients can develop ipsilateral upper extremity compartment syndrome. The initial management of hyperperfusion syndrome should be guided depending on its etiology. If arterial causes are suspected, the initial management should include (1) elevating the arm and (2) decreasing ECMO flow. The latter maneuver is done to balance adequate end-organ perfusion and capillary pressure in the affected arm. If these maneuvers fail to relieve the syndrome, and concerns regarding the condition of the arm continue to occur, an effort to relocate the outflow for the VA-ECMO should be pursued.

If the cause of hyperperfusion syndrome is venous obstruction, therapy should be aimed at addressing the etiology causing the decreased venous return. For cases in which bleeding is the cause, evacuation of the hematoma impinging on the axillary vein should be performed and wide drainage achieved with sump catheters. Close inspection of the anastomosis is warranted in these cases, because continued bleeding from the arterial anastomotic site will perpetuate the problem. In cases in which a cannula is placed in the axillary vein for VA-ECMO drainage, another vein should be selected for cannulation-preferably the femoral vein. For patients in whom deep venous thrombosis is suspected, or diagnosed by radiologic modalities, no alternative is possible other than changing the arterial cannulation site, as previously described. It is important to note that the venous outflow can also be impeded in cases of cardiac tamponade and relieving this problem will also assist in upper extremity drainage.
Although, ideally, most patients would undergo a workup preoperatively before the axillary artery is used for cannulation, the reality is that most patients present in such an acute state that a thorough radiologic investigation of some of these etiologies is never performed, and most are diagnosed only later. Nonetheless, it is important to keep these events in mind, because at the point of consultation, a good vascular history can provide insight regarding the potential of developing hyperperfusion syndrome after axillary artery cannulation.

It was reassuring to find that the incidence of other adverse events associated with axillary artery side grafting for VA ECMO was not high. The incident of stroke with this technique in our series was $6.2 \%$, lower than that of other published reports on ECMO using different cannulation strategies. ${ }^{8}$ It is imperative to note that a number of other factors can cause stroke, notwithstanding complex surgical procedures and/or the volatile hemodynamic fluctuations seen in patients who need ECMO support.

The incidence of upper extremity neurologic and stump graft infection as adverse events at the last follow-up visit was also low. Although neuropraxy did develop in our series, they were few and not permanent and resolved with a combination of physical therapy and expectant waiting.

Finally, an important point that should be underscored from this experience is that the findings we have reported might be relevant when considering the use of the side graft axillary artery technique to establish long-term mechanical circulatory support. For instance, with left ventricular assist devices becoming smaller, and the population of patients with ischemic cardiomyopathy increasing, procedures could evolve for using this anastomotic technique as a location for the left ventricular assist device outflow graft when using limited incisions. It is reasonable to believe that some surgeons might use it, in particular, for cases in which a patient has undergone previous sternotomy and, as a result, the surgeon might want to avoid sternal re-entry. In such cases, a thorough workup would be needed to avoid hyperperfusion syndrome if the axillary artery is selected as the target vessel for left ventricular assist device drainage.

\section{CONCLUSIONS}

The axillary artery side graft is more frequently associated with hyperperfusion syndrome in VA ECMO. Lower extremity ischemia and compartment syndrome are more common after femoral arterial cannulation. Continuous surveillance is necessary to identify complications early, and surgical revision could be required to manage those complications.

\section{References}

1. Blythe D. Percutaneous axillary artery insertion of an intra-aortic balloon pump Anesth Intensive Care. 1995;23:406-7. 
2. Edmunds LH Jr, Herrmann HC, DiSesa VJ, Ratcliffe MB, Bavaria JE, McCarthy DM. Left ventricular assist without thoracotomy: clinical experience with the Dennis method. Ann Thorac Surg. 1994;57:880-5.

3. Gillinov AM, Sabik JF, Lytle BW, Cosgrove DM. Axillary artery cannulation. J Thorac Cardiovasc Surg. 1999;118:1153.

4. Kaplon RJ, Smedira NG. Extracorporeal membrane oxygenation in adults. In: Golstein DJ, Oz MC, eds. Cardiac assist devices. Armonk, NY: Futura Publishing; 2000:263-73

5. Navia JL, Atik FA, Beyer EA, Ruda VP. Extracorporeal membrane oxygenation with right axillary artery perfusion. Ann Thorac Surg. 2005;79:2163-5.
6. Sabik JF, Lytle BW, McCarthy PM, Cosgrove DM. Axillary artery: an alternative site of arterial cannulation for patients with extensive aortic and peripheral vascular disease. J Thorac Cardiovasc Surg. 1995;109:885-90.

7. Pokersnik JA, Buda T, Bashour CA, Gonzalez-Stawinski GV. Have changes in ECMO technology impacted outcomes in adult patients developing postcardiotomy cardiogenic shock? J Card Surg. 2012;27:246-52.

8. Rastan AJ, Dege A, Mohr M, Doll N, Falk V, Walther T, et al. Early and late outcomes of 517 consecutive adult patients treated with extracorporeal membrane oxygenation for refractory postcardiotomy cardiogenic shock. J Thorac Cardiovasc Surg. 2010;139:302-11.

Access to The Journal of Thoracic and Cardiovascular Surgery Online is reserved for print subscribers!

Full-text access to The Journal of Thoracic and Cardiovascular Surgery Online is available for all print subscribers. To activate your individual online subscription, please visit The Journal of Thoracic and Cardiovascular Surgery Online, point your browser to http://www.mosby.com/itcvs, follow the prompts to activate your online access, and follow the instructions. To activate your account, you will need your subscriber account number, which you can find on your mailing label (note: the number of digits in your subscriber account number varies from 6 to 10 ). See the example below in which the subscriber account number has been circled:

\section{Sample mailing label}

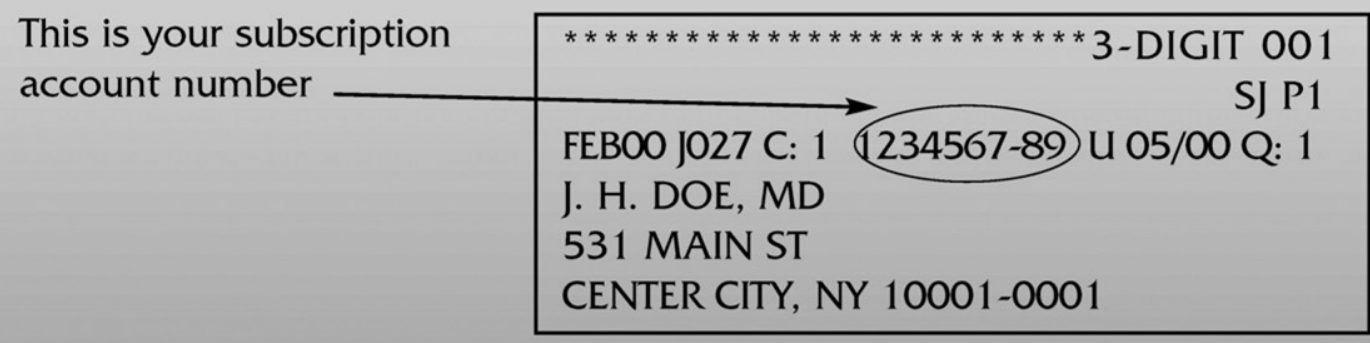

Personal subscriptions to The Journal of Thoracic and Cardiovascular Surgery Online are for individual use only and may not be transferred. Use of The Journal of Thoracic and Cardiovascular Surgery Online is subject to agreement to the terms and conditions as indicated online. 